\title{
Gene signatures with predictive and prognostic survival values in human osteosarcoma
}

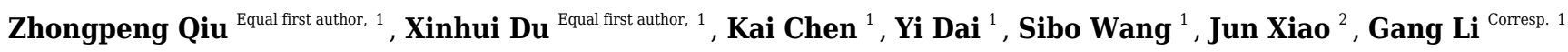 \\ ${ }^{1}$ Trauma department of orthopedics, First Affiliated Hospital, School of Medicine, Shihezi University, Shihezi, Xinjiang, China \\ 2 School of Medicine, Shihezi university, Shihezi, Xinjiang, China \\ Corresponding Author: Gang Li \\ Email address: ligang_shzu@shzu.edu.cn
}

Osteosarcoma is a common malignancy seen mainly in children and adolescents. The disease is characterized by poor overall prognosis and lower survival due to a lack of predictive markers. Many gene signatures with diagnostic, prognostic, and predictive values were evaluated to achieve better clinical outcomes. Two public data series, GSE21257 and UCSC Xena, were used to identify the minimum number of robust genes needed for a predictive signature to guide prognosis of patients with osteosarcoma. The lasso regression algorithm was used to analyze sequencing data from TCGA-TARGET, and methods such as Cox regression analysis, risk factor scoring, receiving operating curve, KMplot prognosis analysis, and nomogram were used to characterize the prognostic predictive power of the identified genes. Their utility was assessed using the GEO osteosarcoma dataset. Finally, the functional enrichment analysis of the identified genes was performed. A total of twenty-gene signatures were found to have a good prognostic value for predicting patient survival. Gene ontology analysis showed that the key genes related to osteosarcoma were categorized as peptide-antigen binding, clathrin-coated endocytic vesicle membrane, peptide binding, and MHC class II protein complex. The osteosarcoma related genes in these modules were significantly enriched in the processes of antigen processing and presentation, phagocytosis, cell adhesion molecules, Staphylococcus aureus infection. Twenty gene signatures were identified related to osteosarcoma, which would be helpful for predicting prognosis of patients with OS. Further, these signatures can be used to determine the subtypes of osteosarcoma. 
1 Gene signatures with predictive and prognostic survival

2 values in human osteosarcoma

3 Zhongpeng Qiu ${ }^{1}$, Xinhui Du ${ }^{1}$, Kai Chen ${ }^{1}$, Yi Dai ${ }^{1}$, Sibo Wang ${ }^{1}$, Jun Xiao ${ }^{2}$, Gang Li ${ }^{1}$

41 Trauma department of orthopedics, First Affiliated Hospital, School of Medicine, Shihezi University,

5 Shihezi, Xinjiang, China

62 School of Medicine, Shihezi University, Shihezi, Xinjiang, China

7 Corresponding Author:

8 Gang $\mathrm{Li}^{1}$

9 Hongshan Street, Shihezi, Xinjiang Uygur Autonomous Region, 832000, China

Email address: ligang_shzu@shzu.edu.cn

11

12

13

14

15

16

17

18

19

20

21

22

23 


\section{Abstract}

Osteosarcoma is a common malignancy seen mainly in children and adolescents. The disease is characterized by poor overall prognosis and lower survival due to a lack of predictive markers. Many gene signatures with diagnostic, prognostic, and predictive values were evaluated to achieve better clinical outcomes. Two public data series, GSE21257 and UCSC Xena, were used to identify the minimum number of robust genes needed for a predictive signature to guide prognosis of patients with osteosarcoma. The lasso regression algorithm was used to analyze sequencing data from TCGA-TARGET, and methods such as Cox regression analysis, risk factor scoring, receiving operating curve, KMplot prognosis analysis, and nomogram were used to characterize the prognostic predictive power of the identified genes. Their utility was assessed using the GEO osteosarcoma dataset. Finally, the functional enrichment analysis of the identified genes was performed. A total of twenty-gene signatures were found to have a good prognostic value for predicting patient survival. Gene ontology analysis showed that the key genes related to osteosarcoma were categorized as peptide-antigen binding, clathrin-coated endocytic vesicle membrane, peptide binding, and MHC class II protein complex. The osteosarcoma related genes in these modules were significantly enriched in the processes of antigen processing and presentation, phagocytosis, cell adhesion molecules, Staphylococcus aureus infection. Twenty gene signatures were identified related to osteosarcoma, which would be helpful for predicting prognosis of patients with OS. Further, these signatures can be used to determine the subtypes of osteosarcoma.

\section{Introduction}

Osteosarcoma (OS) is a common primary malignancy seen mainly in children and adolescents(Yang et al., 2018). Its annual incidence ranges from 2 to 3 in 1 million people(de Azevedo et al., 2020), and it accounts for $40.51 \%$ of primary bone malignancies(Li et al., 2020). The incidence of OS is higher in males than in females(Damron et al., 2007), and it accounts for $15 \%$ of all extracranial tumors in the 10-19-year-old age group)(Nie \& Peng, 2018). It is considered the third most common cancer in adolescence(Zhang et al., 2018). OS treatment is aggressive and combines neoadjuvant chemotherapy, extensive surgical resection, and additional postoperative adjuvant chemotherapy. Five-year survival rate of non-metastatic patients is $65 \%-$ $70 \%$ (Siegel et al., 2018). Regarding patients with distant metastases, 5-year survival rate is only 15\%-30\%(Whelan \& Davis, 2018). Further, relapse rate remains high at approximately 35\%(Yu et al., 2014). Metastasis remains the main cause of death in patients with OS. Many prognostic factors are reported to be related to OS: miR-195, miR-21, TGF- $\beta$, MMP-9, HIF-1, APE1, and COX2. However, use of these factors has not improved survival rate related to OS(Zamborsky et al., 2019). Therefore, clarifying the molecular mechanisms underlying the occurrence and progression of OS and exploring the potential diagnostic and therapeutic targets are of great importance for the diagnosis and treatment of OS. Many biomarkers have been evaluated (Table 1)(Wan-Ibrahim et al., 2015), but none have been approved by the Food and Drug Administration for clinical settings (Wan-Ibrahim et al., 2015). This lack may be due to research deficiencies, unacceptable heterogeneity, or absence of effective evaluation. Biomarkers for patients with OS, particularly those with metastases, are urgently needed for early diagnosis and 
establishment of treatment goals. Serum biomarkers are used for predicting prognosis of other cancers but are rarely characterized in OS(Zamborsky et al., 2019). An obvious need in OS is effective biomarkers for characterizing disease progression and associated prognosis.

One study reported that CDC20 and its downstream substrates, secure, cyclin A2 and cyclin B2 are good prognostic factors for OS(Wu et al., 2019). Savage et al(Jin et al., 2007). suggested that two loci in the GRM4 gene at 6p21.3 and in the gene, desert, at 2p25.2, These two loci warrant further exploration to uncover the biological mechanisms underlying susceptibility to osteosarcoma.The study addressed a single gene and did not take into account interactions among molecules that regulate tumorigenesis. Three candidate genes (ALOX5AP, CD74 and FCGR2A) were found. Their expression levels in lung and lymph nodes were higher than levels in matched cancer tissues, and they may be expressed in microenvironments(Li et al., 2020). Some limitations exist in these studies. First, accuracy cannot be guaranteed with only one dataset because of an expected high false-positive rate. Further, using a single high-throughput analysis method (only sequencing or chip data), results obtained will be biased. Second, a patient's sample data are too limited. Finally, clinical information is incomplete.

Identifying the minimum number of robust genes needed to produce a predictive signature for prognosis for patients with OS was the objective of this study. The lasso regression algorithm was used to analyze sequencing data from TCGA-TARGET, and Cox regression analysis, risk factor score, receiving operating curve (ROC), KMplot prognosis analysis, nomogram and other methods were used to assess genes for their predictive power. Next, the accuracy and predictive power of twenty-gene identified in this process were assessed using the GEO OS dataset. Finally, we performed functional enrichment analysis on these twenty-gene.

\section{Material and Methods}

\subsection{Data collection and preprocessing}

Training set: The TARGET-OS RNA-sequencing dataset (presented as fragments per kilobase million, FPKM), corresponding clinical characteristics and prognosis information were downloaded from UCSC Xena (Goldman et al., 2019)(https:/xena.ucsc.edu/). Patients with expression profiles but no prognostic information and clinical characteristics were excluded. Finally, 84 patients with OS were included in a training set. FPKM data were converted to TPM data and annotated using gencode.v22.annotation.gene.probeMap.

Validation set: The gene expression data GSE21257(Buddingh et al., 2011) (GPL570 (HGU133_Plus_2) Affymetrix Human Genome U133 Plus 2.0 Array) for 53 patients with OS were downloaded from the GEO database, and corrected and annotated with R software.

\subsection{Construction of gene signatures}

A linear regression multiple regression model was developed for the underlying expression levels of genes for prognostic risk scores. The method chosen by lasso Cox was 10-fold crossvalidation. According to the median cutoff value (the cutoff value refers to the content before the brackets of the HR value in each dataset) of the risk score, patients with OS were divided into high-risk and low-risk groups. Model prediction efficiency using the training set was evaluated by Kaplan-Meier log-rank test, time-dependent ROC curve analysis, Cox regression analysis, 
111

112

113

114

115

116

117

118

119

120

121

122

123

124

125

126

127

128

129

130

131

132

133

134

135

136

137

138

139

140

141

142

143

144

145

146

147

148

and risk factor score for validation and test sets. A nomogram was constructed using Iasso's guidelines.

\subsection{Weighted correlation network analysis of genes}

Based on the variance of gene expression in TARGET-OS data, the top 5000 genes were selected for WGCNA(Langfelder \& Horvath, 2008). This analysis proceeded as: check for outliers in all samples, construct sample tree with hclust, and remove outliers according to cut height. To explore the correlation between expression data and clinical phenotypes, the sample tree and characteristic heat map were visualized. Subsequently, the strength of associations between pairs of nodes of the adjacency matrix aij was calculated as: $\mathrm{sij}=|\operatorname{cor}(\mathrm{xi}, \mathrm{xj})|$ aij $=\mathrm{Sij} \beta$. $\mathrm{xi}$ and $\mathrm{xj}$ are genes $\mathrm{i}$ and $\mathrm{j}$. The vector of expression value, sij, indicates the strength of Pearson's correlation coefficient between genes $i$ and $j$. The aij coding network connects genes $i$ and $j$. $\beta$ value is a soft threshold (power value). Further, the Scale-Free Topology Fit Index (scale-free R2) range from 0 to 1 is used to determine the scale-free topological model. Selecting a set of soft threshold powers (range: 1 to 20 ) assists in calculating scale-free topological model fitting. The soft threshold of $\beta=7$ was used to define the adjacency matrix. The corresponding scale-free $\mathrm{R} 2$ value is 0.87 , suggesting a satisfactory scale-free topology model.

In coexpression networks, the highest absolute association genes were clustered into the same module to generate a clustering dendrogram. Relationships between clinical traits and risk scores were analyzed by Pearson correlation and results were visualized by heat map analysis. Genes in the module were analyzed for gene ontology (GO) and KEGG pathway enrichment. Moreover, Cytoscape(Smoot et al., 2010) (version 3.7.2) was used to visualize the weighted coexpression network. gene ontology (GO) analysis, which includes annotation of biological processes (BPs), molecular functions (MFs), and cellular components (CCs), serves as a major bioinformatics tool to annotate genes and analyze the biological processes of these genes. Huimei Wang et al analyzed the biological classification of DEGs, showing that changes in BPs of DEGs were significantly enriched in positive regulation of associated cell response, by GO analysis(Wang et al. 2018).

\subsection{Functional enrichment analysis}

Clusterprofiler(Yu et al., 2012) was used to study modules related to biological function for determining functional and pathway enrichment. A multiple testing correction was performed using hypergeometric test functions and the Benjamini-Hochberg method. The GOplot (Walter et al., 2015) package was used to visualize the enrichment analysis.

\section{$3 \quad$ Statistical analysis}

Statistical analysis was conducted in R software (version 3.6.1) with the following packages: "glmnet"(Friedman et al., 2009), "survivalROC" (Heagerty et al., 2000), "WGCNA," and "clusterProfiler." All the statistical tests were two sided, and P-values of $<0.05$ were considered statistically significant. 
149

150

151

152

153

154

155

156

157

158

159

160

161

162

163

164

165

166

167

168

169

170

171

172

173

174

175

176

177

178

179

180

181

182

183

184

185

186

187

188

189

\section{Results}

\subsection{Construction of genes classifier for OS}

Prognostically significant genes for OS in TARGET-OS data were analyzed and a total of 1151 genes were significantly associated with poor prognosis. These 1151 candidate genes were included in the lasso prognostic classifier for further screening and model construction. A twenty-gene classifier for the OS was developed (Figure 1A and 1B). The gene information in the model is shown in Table 1. Patients were divided into a high-risk group $(n=42)$ and low-risk group $(n=42)$ based on risk scores. The median risk score was set as the cutoff (the cutoff value refers to the content before the brackets of the HR value in each dataset). Table 2 shows clinical characteristics of patients with OS in the training set according to their high risk and low risk scores. The Kaplan-Meier log-rank test suggested a significant difference between high-risk and low-risk groups in the training set $(P<0.001$; Figure $1 \mathrm{C})$. In the time-dependent analysis of the ROC curve, AUCs for OS in the first, third, and fifth years were 0.94, 0.98, and 0.97, respectively (Figure 1D).

\subsection{Identification of a prognostic risk score model based on the training set}

Based on univariate regression analysis (Cox's proportional hazard model), forest plots of selected genes with $p$-value and hazard ratios are shown in Figure 2A. HR, Hazard Rate in Figure $2 \mathrm{~A}$, shows that the p-value of selected genes was less than 0.05 , showing the statistical difference, which cannot be ignored. Only when $95 \%$ CI conclude 1 , it could be proved that these selected genes signatures were not significantly associated with the prognosis of patients with OS. Although the extremum of HR is very close to 1, they show that these selected genes might be associated with the prognosis of patients with OS. Risk scores and survival status of patients with $\mathrm{OS}$ are shown in Figure $2 \mathrm{~B}$ and $2 \mathrm{C}$, respectively. These results indicate that patients with high risk scores have poor outcomes compared with patients with low risk scores (Figure 2D). Using these data, a nomogram combining the classifier with clinicopathological features to predict the survival probability of patients with different risk scores was prepared (Figure 3A). The calibration chart demonstrated that predicted three-year and five-year survival rates were very close to observed ratios (Figure 3B).

\subsection{Validation of twenty-gene signature for survival prediction in the validation set}

Subsequently, the validation set was used to assess the power of the twenty-gene signature in predicting prognosis. OS of the low-risk group was superior to the high-risk group $(P<0.05$; Figure 4A). Also, time-dependent ROC analysis is used to assess the effectiveness of risk models in predicting outcomes. Areas under ROC was $0.81,0.78$, and 0.76 at one, three and five years, respectively, suggesting that the twenty-gene signature displays good predictive power (Figure 4B). The C-index value is 0.944 . The risk score (Figure 4C) and survival status (Figure 4D) of patients with OS, and distribution of risk scores of twenty-gene expression profiles are shown in a heat map of 53 patients in the validation set (Figure 4E). These results suggest that the twentygene signature shows good prognostic value for patient survival. This finding is further validated since patients with high risk scores were associated with poorer prognoses compared with patients with low risk scores. Previous studies have investigated gene factors in an attempt to identify new prognostic OS markers(Goh et al. 2019; Guan et al. 2020). Hence, I have 
190

191

192

193

194

195

196

197

198

199

200

201

202

203

204

205

206

207

208

209

210

211

212

213

214

215

216

217

218

219

220

221

222

223

224

225

226

227

228

229

230

231

compared the prognostic gene set for osteosarcoma, Cox univariate and multivariate analysis showed that BACE2, ING2 ALOX5AP, HLA-DMB, HLA-DRA, and SPINT2 were not the independent prognostic factors for osteosarcoma (Table 3). Table 3 shows the determinants of BACE2, ING2 ALOX5AP, HLA-DMB, HLA-DRA, and SPINT2 for all the patients. In the univariate analysis, These gene signatures exhibited a negative correlation with age, gender, specific and primary tumor site, but illustrate a positive correlation with recurrence and risk score. After multiple stepwise analysis, these biomarkers correlated independently with Recurrence (hazard ratio (HR) 5.374, 95\% CI 1.183-24.404, $\mathrm{p}=0.029)$ and risk score (HR 9.869, 95\% CI 4.663-20.887, $\mathrm{p}<0.001)$.

\subsection{Gene co-expression network analysis}

The relationship between risk scores and gene expression profiles was evaluated using the top 5000 genes in the variance filter for WGCNA analysis. The red line (cut height $=8000$ ) was used to remove the abnormal samples in the sample tree. TARGET-40-PAUXOZ-01A was excluded after removing outliers (Figure 5). The sample dendrogram and trait heat map placed selected samples into different sample clusters that provided clinical trait information (Figure 6A). Independence and average connectivity of coexpression modules were determined by power $(\beta)$ and scale $\mathrm{R}^{2}$ value. A series of soft thresholds and corresponding performance power were plotted. The threshold for scale $\mathrm{R}^{2}$ value was set at 0.85 . The power value of seven is the threshold that first reaches the scale $\mathrm{R}^{2}$ value, and was chosen as the soft threshold to construct and identify coexpression modules (Figure 6B and 6C). The expression matrix was converted to an adjacency matrix, and subsequently into a topology matrix. Based on TOM, genes are clustered based on criteria of mixed dynamic shear trees using average connection-level distance. The minimum number of genes in each module was set at 7. Finally, a total of 11 modules were identified with the WGCNA package (Figure 6D). Statistics of gene numbers in each module are shown in Table 4. Associations of these modules with clinical characteristics (including sex, age, relapse, OS, metastasis, major cancer sites, specific cancer sites, and risk scores) are shown in Figure 6E. T module showed the highest correlation with the risk score. Further, the magenta module also was negatively correlated with sex and OS and positively correlated with major cancer sites. GSEA analysis between high-risk and low-risk groups can better illustrate the risk-score related to the biological process. But GSEA analysis between highrisk and low-risk groups only considers the expression level of gene sets. Analysis of WGCNA is based on the clinical relevant factors, which makes it sense, although its risk-score is low.

\subsection{Functional enrichment analysis in the gene coexpression network of the magenta module}

GO and KEGG enrichment analysis was used to characterize biological functions of genes in the magenta module as they related to risk scores. GO analysis showed that key genes related to OS were mainly enriched in peptide-antigen binding, clathrin-coated endocytic vesicle membrane, peptide binding, and MHC class II protein complex (Figure 7A). KEGG analysis showed that the key genes related to OS were mainly enriched in antigen processing and presentation, phagosome, cell adhesion molecules, Staphylococcus aureus infection (Figure 7B). Subsequently, the interaction network for enrichment pathways in the magenta module was 
232

233

234

235

236

237

238

239

240

241

242

243

244

245

246

247

248

249

250

251

252

253

254

255

256

257

258

259

260

261

262

263

264

265

266

267

268

269

270

271

272

273

visualized (Figure 7C). Moreover, an interaction network was constructed to visualize genes in the coexpression magenta module (Figure 7D).

\section{Discussion}

OS is a disease involving complex interactions among many factors. Overall, OS disrupts cell signaling pathways, causing loss of bone tissue homeostasis(Otoukesh et al., 2018). The urgent need to obtain better clinical results highlights the related need for better diagnostic, prognostic, and predictive biomarkers(Ludwig \& Weinstein, 2005). Presently, no specific markers are available for OS diagnosis. To reduce mortality and increase limb salvage, biomarkers are needed for early identification of disease(Smida et al., 2017). Possible genetic biomarkers to address this need were identified in the present study. Lasso regression screened in twenty-gene in a training set. These genes have certain prognostic value in time ROC, risk factor, and Kaplan-Meier plots. Results were verified with a validation set.

One current study showed that inhibition of BNIP3 expression by baicalein treatment could inhibit cell apoptosis(Ye et al., 2015). Moreover, the MYC gene is also reported to be amplified in a subset of OS(Ladanyi et al., 1993). MYC promotes the proliferation of OS cells through the autophagy pathway(Mo et al., 2019). Cross-species genomics identified DLG2 as a tumor suppressor in OS(Shao et al., 2019). Further, depletion of KIF25 leads to the formation of actin stress fibers, which may be due to the changes of Rho signaling observed before microtubule destabilization(Wittmann \& Waterman-Storer, 2001). In addition to the above studies of genes related to OS, relationships between other genes screened in this study and malignancies have been reported in the literature but have not been reported in OS. A lack of related research reports to help assess the potential of these genes as targets for the treatment and diagnosis of OS currently exits.

The current study also explored the relationship between risk scores and gene expression profiles using WGCNA analysis. Important genes related to OS were enriched in 11 different modules. Results showed that pathways related to inflammation and immunity were primarily enriched in the turquoise module. The gray and turquoise modules share the most pathways among all pairwise comparisons. Genes in these modules may play similar roles in OS.

LASSO is a method of shrinking and variable selection linear regression model. The purpose of LASSO regression is to obtain a subset of the predictors to minimize the prediction errors of the quantitative response variables. The lasso does this by constraining the model parameters, making the regression coefficients of some variables approach 0. "Coxnet" fits a lasso penalty, and its adaptive forms, such as adaptive lasso. Moreover, it treats the number of non-zero coefficients as another tuning parameter and simultaneously selects with the regularization parameter "lambda". And Yanlu Xiong et al established a 13 gene-based survival score for prognostic prediction of Lung adenocarcinoma. They filtrated the relevant gene by LASSO and identified the wide applicability of these genes (Xiong et al., 2020).

Previous studies report that CXCR3 may be an independent prognostic risk factor, suggesting a possible benefit of immunotherapy for OS(Tang et al., 2019). The susceptibility and severity of OS may also be related to functional polymorphism of inflammatory genes(Oliveira et al., 2007). Another study has shown that increased expression of MIF indicates an increased risk of metastasis, and MIF is related to angiogenesis and cell infiltration of OS. MIF can be used as a

Peer] reviewing PDF | (2020:07:50718:1:2:NEW 19 Nov 2020) 
274

275

276

277

278

279

280

281

282

283

284

285

286

287

288

289

290

291

292

293

294

295

296

297

298

299

300

301

302

303

304

305

306

307

308

309

310

311

312

313

314

315

316

317

318

319

320

321

322

323

prognostic marker of OS and a potential therapeutic target(Kim et al., 2008). Therefore, clarifying molecular mechanisms of OS may facilitate the identification of novel therapeutic and prognostic targets. Limitations to the study exist. First, although these twenty-gene were identified to have certain prognostic value for OS, all data analyzed in the study were retrieved from the online databases. Thus, further experimental evidence, such as real-time PCR, western blot, immunohistochemistry assays, is required to fully elucidate the role of 20-gene signatures. Second, to determine the diagnostic accuracy of gene associations, a larger sample size would be useful for additional internal validation. Third, assessment of all clinically relevant influencing factors for OS was not included, and more clinical information and PFS-related data are needed. Finally, differentially expressed genes were not evaluated and nor was the need to add a normal control group and joint verification of multiple tumor sites.In conclusion, the current study proposes a 20-gene signature for diagnostic and prognostic purposes for OS. The twenty-gene signature is independently related to prognostic parameters of OS classification. Also, the signature is a good classifier for different subtypes of patients with OS. This signature may provide a new perspective on the prognosis of OS. The biological functions and pathways enriched in specific modules will be beneficial to the development of new therapeutic methods for the treatment of OS.

\section{$6 \quad$ References}

Buddingh, E.P., Kuijjer, M.L., Duim, R.A.J., Bürger, H., Agelopoulos, K., Myklebost, O., Serra, M., Mertens, F., Hogendoorn, P.C.W., Lankester, A.C., and Cleton-Jansen, A. 2011. Tumor-Infiltrating Macrophages Are Associated with Metastasis Suppression in High-Grade Osteosarcoma: A Rationale for Treatment with Macrophage Activating Agents. CLINICAL CANCER RESEARCH 17:2110. 10.1158/1078-0432.CCR-10-2047

Damron, T.A., Ward, W.G., and Stewart, A. 2007. Osteosarcoma, Chondrosarcoma, and Ewing's Sarcoma: National Cancer Data Base Report. Clinical Orthopaedics and Related Research ${ }^{\circledR} 459$.

de Azevedo, J.W.V., Fernandes, T.A.A.D., Fernandes, J.V., de Azevedo, J.C.V., Lanza, D.C.F., Bezerra, C.M., Andrade, V.S., de Araújo, J.M.G., and Fernandes, J.V. 2020. Biology and pathogenesis of human osteosarcoma (Review). Oncology Letters 19:1099-1116. 10.3892/ol.2019.11229

Friedman, J., Hastie, T., and Tibshirani, R. 2009. Glmnet: Lasso and elastic-net regularized generalized linear models. R Package Version 1.

Goldman, M., Craft, B., Hastie, M., Repečka, K., McDade, F., Kamath, A., Banerjee, A., Luo, Y., Rogers, D., Brooks, A.N., Zhu, J., and Haussler, D. 2019. The UCSC Xena platform for public and private cancer genomics data visualization and interpretation. bioRxiv:326470. 10.1101/326470

Heagerty, P.J., Lumley, T., and Pepe, M.S. 2000. Time-Dependent ROC Curves for Censored Survival Data and a Diagnostic Marker. BIOMETRICS 56:337-344. 10.1111/j.0006-341X.2000.00337.x

Jin, S., Shen, J., Guo, Q., Zhou, J., Wang, J., Huang, G., Zou, C., Yin, J., Liu, S., Liu, W., Li, M., and Wang, L. 2007. 2-D DIGE and MALDI-TOF-MS analysis of the serum proteome in human osteosarcoma. PROTEOMICS Clinical Applications 1:272-285. 10.1002/prca.200600869

Kim, H., Han, I., Lee, M., Oh, J.H., and Kim, E.H. 2008. Expression of macrophage migration inhibitory factor (MIF) is related to prognosis in osteosarcoma. CANCER RESEARCH 68:5344.

Ladanyi, M., Park, C.K., Lewis, R., Jhanwar, S.C., Healey, J.H., and Huvos, A.G. 1993. Sporadic amplification of the MYC gene in human osteosarcomas. Diagnostic molecular pathology : the American journal of surgical pathology, part B 2:163-167.

Langfelder, P., and Horvath, S. 2008. WGCNA: an R package for weighted correlation network analysis. $B M C$ BIOINFORMATICS 9:559. 10.1186/1471-2105-9-559

Li, M., Jin, X., Li, H., Wu, G., Wang, S., Yang, C., and Deng, S. 2020. Key genes with prognostic values in suppression of osteosarcoma metastasis using comprehensive analysis. BMC CANCER 20:65. 10.1186/s12885-0206542-z

Ludwig, J.A., and Weinstein, J.N. 2005. Biomarkers in Cancer Staging, Prognosis and Treatment Selection. NATURE REVIEWS CANCER 5:845-856. 10.1038/nrc1739

Mo, H., He, J., Yuan, Z., Wu, Z., Liu, B., Lin, X., and Guan, J. 2019. PLK1 contributes to autophagy by regulating

Peer] reviewing PDF | (2020:07:50718:1:2:NEW 19 Nov 2020) 
324

325

326

327

328

329

330

331

332

333

334

335

336

337

338

339

340

341

342

343

344

345

346

347

348

349

350

351

352

353

354

355

356

357

358

359

360

361

362

363

364

365

366

367

368

369

370

371

372

373

374

375

376

377

378

379

MYC stabilization in osteosarcoma cells. Onco Targets Ther 12:7527-7536. 10.2147/OTT.S210575

Nie, Z., and Peng, H. 2018. Osteosarcoma in patients below 25 years of age: An observational study of incidence, metastasis, treatment and outcomes. Oncology Letters 16:6502-6514. 10.3892/ol.2018.9453

Oliveira, I.D., Petrilli, A.S., Tavela, M.H., Zago, M.A., and de Toledo, S.R.C. 2007. TNF-alpha, TNF-beta, IL-6, IL10, PECAM-1 and the MPO Inflammatory Gene Polymorphisms in Osteosarcoma. Journal of Pediatric Hematology/Oncology 29.

Otoukesh, B., Boddouhi, B., Moghtadaei, M., Kaghazian, P., and Kaghazian, M. 2018. Novel molecular insights and new therapeutic strategies in osteosarcoma. Cancer Cell International 18:158. 10.1186/s12935-018-0654-4

Shao, Y.W., Wood, G.A., Lu, J., Tang, Q., Liu, J., Molyneux, S., Chen, Y., Fang, H., Adissu, H., McKee, T., Waterhouse, P., and Khokha, R. 2019. Cross-species genomics identifies DLG2 as a tumor suppressor in osteosarcoma. ONCOGENE 38:291-298. 10.1038/s41388-018-0444-4

Siegel, R.L., Miller, K.D., and Jemal, A. 2018. Cancer statistics, 2018. CA: A Cancer Journal for Clinicians 68:7-30. $10.3322 /$ caac. 21442

Smida, J., Xu, H., Zhang, Y., Baumhoer, D., Ribi, S., Kovac, M., von Luettichau, I., Bielack, S., O'Leary, V.B., Leib-Mösch, C., Frishman, D., and Nathrath, M. 2017. Genome-wide analysis of somatic copy number alterations and chromosomal breakages in osteosarcoma. INTERNATIONAL JOURNAL OF CANCER 141:816-828. 10.1002/ijc.30778

Smoot, M.E., Ono, K., Ruscheinski, J., Wang, P., and Ideker, T. 2010. Cytoscape 2.8: new features for data integration and network visualization. BIOINFORMATICS 27:431-432. 10.1093/bioinformatics/btq675

Tang, Y., Gu, Z., Fu, Y., and Wang, J. 2019. CXCR3 from chemokine receptor family correlates with immune infiltration and predicts poor survival in osteosarcoma. BIOSCIENCE REPORTS 39. 10.1042/BSR20192134

Walter, W., Sánchez-Cabo, F., and Ricote, M. 2015. GOplot: an R package for visually combining expression data with functional analysis. BIOINFORMATICS 31:2912-2914.10.1093/bioinformatics/btv300

Wan-Ibrahim, W.I., Singh, V.A., Hashim, O.H., and Abdul-Rahman, P.S. 2015. Biomarkers for Bone Tumors: Discovery from Genomics and Proteomics Studies and Their Challenges. MOLECULAR MEDICINE 21:861-872. 10.2119/molmed.2015.00183

Whelan, J.S., and Davis, L.E. 2018. Osteosarcoma, Chondrosarcoma, and Chordoma. JOURNAL OF CLINICAL ONCOLOGY 36:188-193. 10.1200/JCO.2017.75.1743

Wittmann, T., and Waterman-Storer, C.M. 2001. Cell motility: can Rho GTPases and microtubules point the way? JOURNAL OF CELL SCIENCE 114:3795.

Wu, M., Ma, Q., Liu, D., Li, X., Deng, L., Li, N., Shen, J., Zhao, Z., and Chen, J. 2019. CDC20 and its downstream genes: potential prognosis factors of osteosarcoma. International Journal of Clinical Oncology 24:1479-1489. 10.1007/s10147-019-01500-3

Xiong, Y., Lei, J., Zhao, J., Lu, Q., Feng, Y., Qiao, T., Xin, S., Han, Y., and Jiang, T. 2020. A gene-based survival score for lung adenocarcinoma by multiple transcriptional datasets analysis. BMC CANCER 20:1046. 10.1186/s12885-020-07473-1

Yang, Y., Han, L., He, Z., Li, X., Yang, S., Yang, J., Zhang, Y., Li, D., Yang, Y., and Yang, Z. 2018. Advances in limb salvage treatment of osteosarcoma. Journal of Bone Oncology 10:36-40. https://doi.org/10.1016/j.jbo.2017.11.005

Ye, F., Wang, H., Zhang, L., Zou, Y., Han, H., and Huang, J. 2015. Baicalein induces human osteosarcoma cell line MG-63 apoptosis via ROS-induced BNIP3 expression. Tumor Biology 36:4731-4740. 10.1007/s13277-015-3122-y

Yu, G., Wang, L., Han, Y., and He, Q. 2012. clusterProfiler: an R package for comparing biological themes among gene clusters. Omics : a journal of integrative biology 16:284-287. 10.1089/omi.2011.0118

Yu, W., Tang, L., Lin, F., Li, D., Wang, J., Yang, Y., and Shen, Z. 2014. Stereotactic radiosurgery, a potential alternative treatment for pulmonary metastases from osteosarcoma. INTERNATIONAL JOURNAL OF ONCOLOGY 44:1091-1098. 10.3892/ijo.2014.2295

Zamborsky, R., Kokavec, M., Harsanyi, S., and Danisovic, L. 2019. Identification of Prognostic and Predictive Osteosarcoma Biomarkers. Medical Sciences

$7: 28$.

Zhang, J., Lan, Q., and Lin, J. 2018. Identification of key gene modules for human osteosarcoma by co-expression analysis. World Journal of Surgical Oncology 16:89. 10.1186/s12957-018-1381-y

Goh TS, Lee JS, Il Kim J, Park YG, Pak K, Jeong DC, Oh S-O, and Kim YH. 2019. Prognostic scoring system for osteosarcoma using network-regularized high-dimensional Cox-regression analysis and potential therapeutic targets. Journal of Cellular Physiology 234:13851-13857. 10.1002/jcp.28065

Guan X, Guan Z, and Song C. 2020. Expression profile analysis identifies key genes as prognostic markers for metastasis of osteosarcoma. Cancer Cell Int 20:104. 10.1186/s12935-020-01179-x 
380 Wang H, Xie Q, Ou-Yang W, and Zhang M. 2018. Integrative analyses of genes associated with idiopathic 381 pulmonary fibrosis. J Cell Biochem. 10.1002/jcb.28153

382 
Figure 1

Construction of comprehensive prognostic classifier based on the training set.

A-10-fold cross-validation for tuning parameter selection in the LASSO model for OS.B-LASSO coefficient profiles of 20 prognostic genes for OS.C-Kaplan-Meier overall survival with a low or high risk of death in the training dataset.D-Time dependent ROC curves at 1, 3 and 5 years for OS $\square$ OS overall survival. 
A

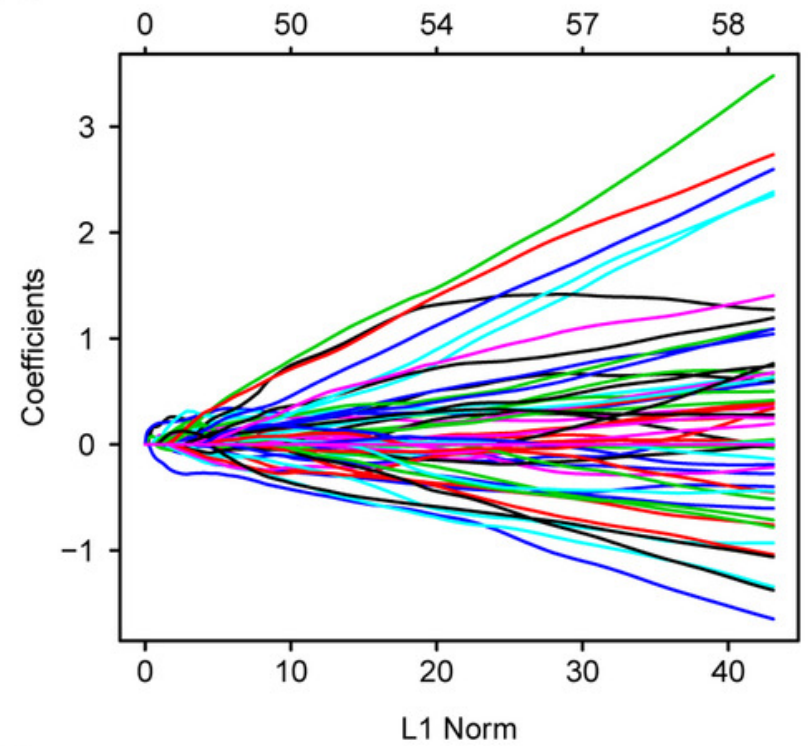

C

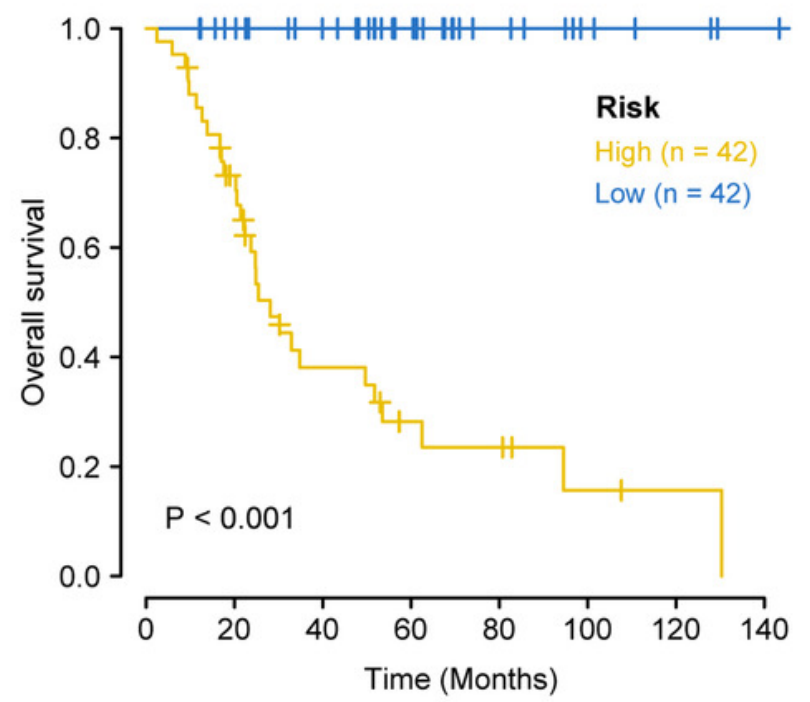

B

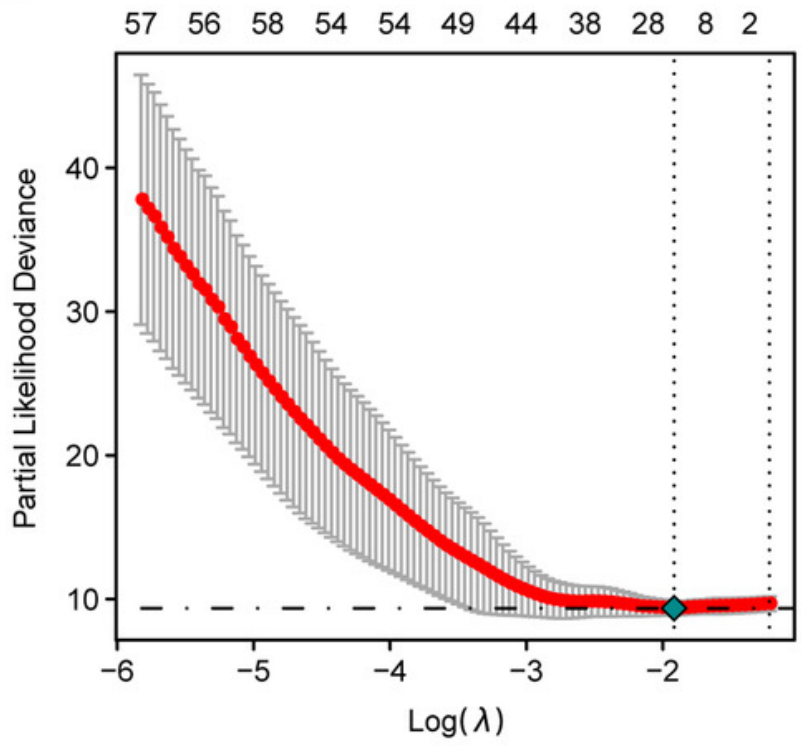

D

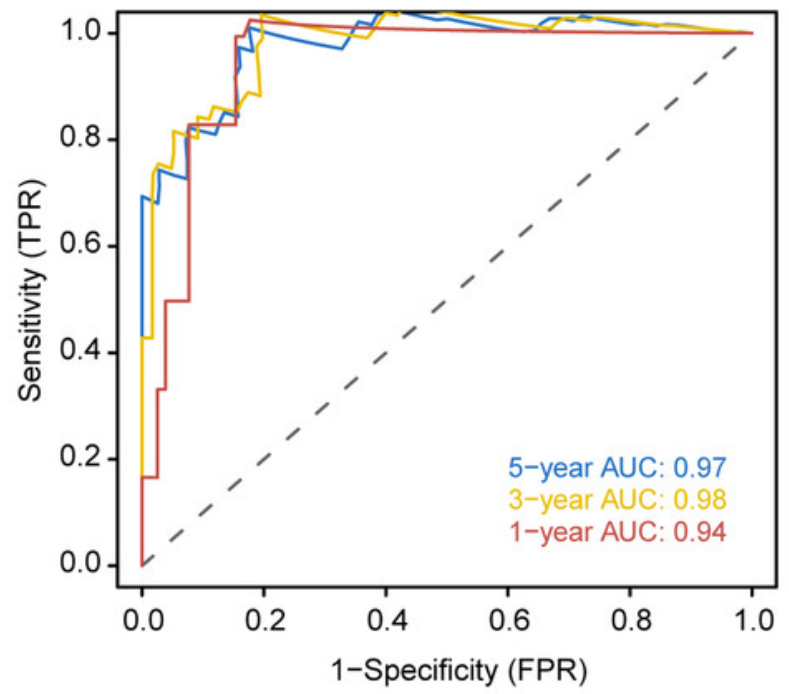




\section{Figure 2}

Multivariate Cox regression analysis was performed for the selected genes, and the risk scores, survival status and risk heat maps of the 20 prognostic genes were distributed in the training set

(A) Hazard ratio distribution for selected 20 key genes. distribution of risk scores, (B)overall survival of 84 patients, and heatmap of 20 genes in prognostic classifier in the training set. The black dotted line suggested the median cutoff divividing patients into low-risk and highrisk groups .

A

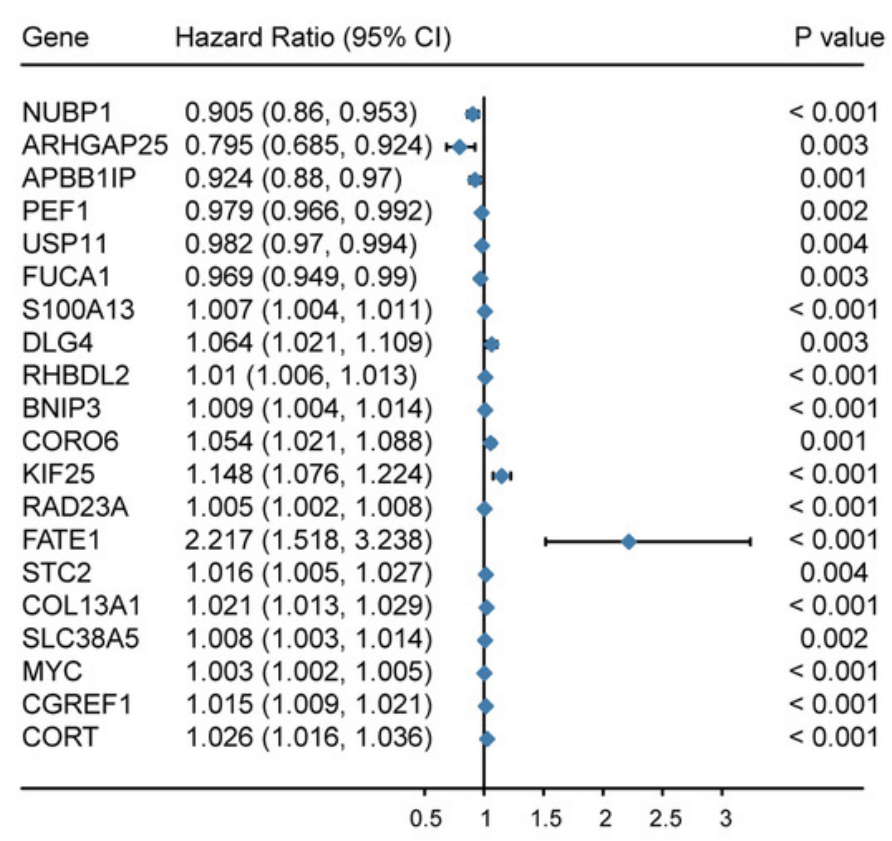

B

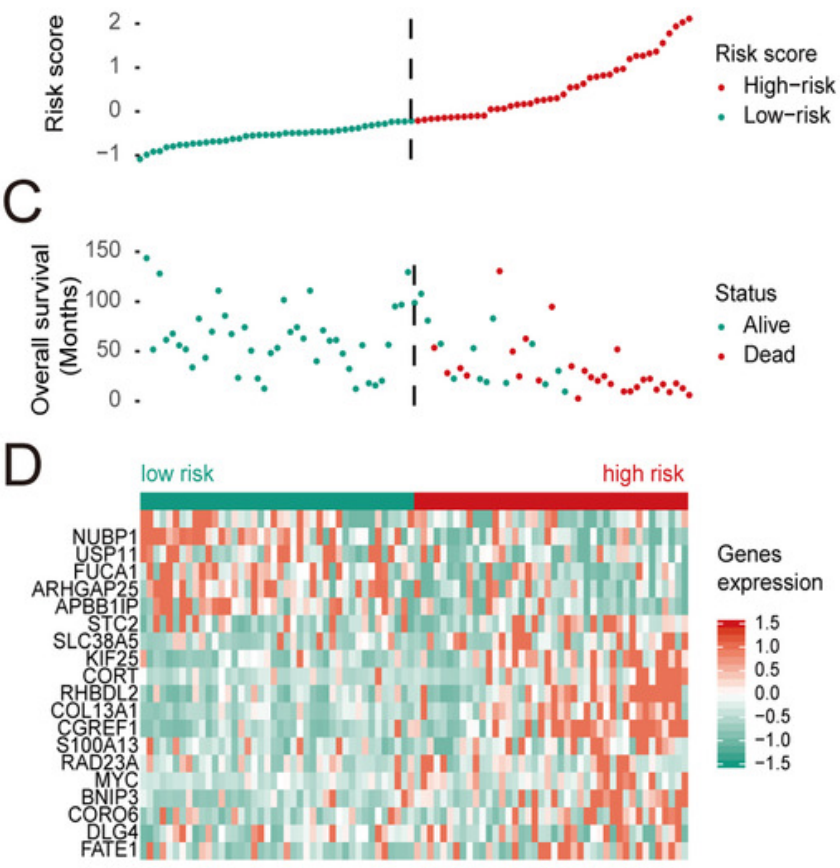




\section{Figure 3}

Nomograms to predict 1-year, 3 - year and 5-year survival probability in osteosarcoma

(A)Total points were obtained by incorporated the corresponding points of recurrence, metastasis, risk score on the point scale. The total points were then converted into specific 1 year, 3- yearand 5-year associated survival probabilities.(B)Calibration plot underlying the nomogram. Dashes show the nomogram-predicted probability for each group, as well as the respective confidence intervals.

A

Points

Recurrence

Metastasis

riskscore

Total Points

Linear Predictor

1-year survival probability

3-year survival probability

5-year survival probability
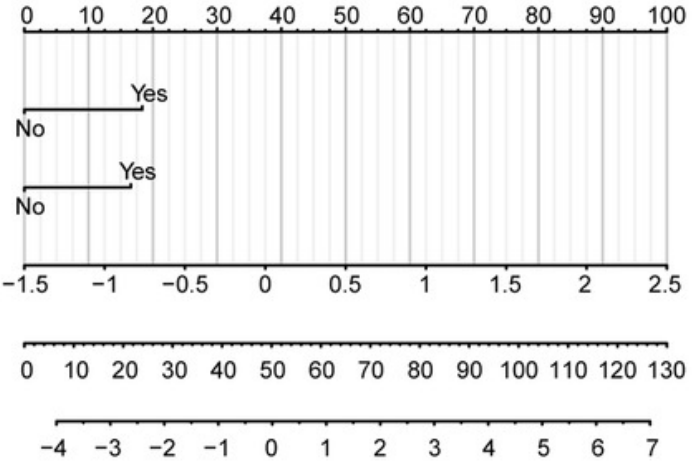

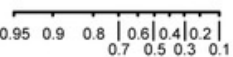

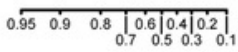

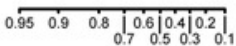

B

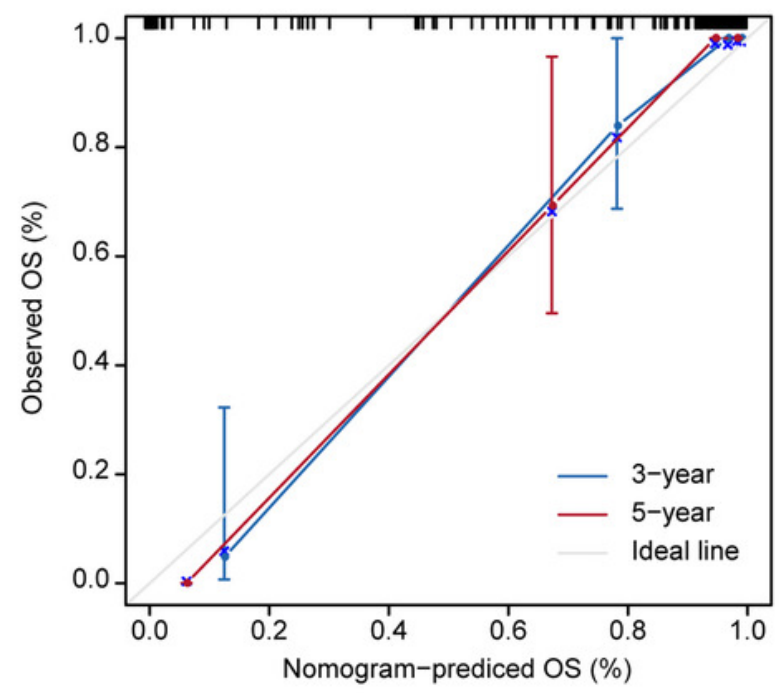


Figure 4

Kaplan-Meier survival, time-dependent ROC curves, and risk score distribution, the overall survival status of 84 patients, and heat maps of the expression of 20 genes in the low and high risk groups based on the validation set

(A)Kaplan-Meier curve of osteosarcoma patients with a low or high risk of death.(B)Time dependent ROC curves at 1, 3, and 5 years for OS in the validation set. (C)Distribution of risk scores for genes in the validation set,(D) overall survival of 53 patients, (E) and heat maps of the expression of 20 genes in the low-risk and high-risk groups.

A

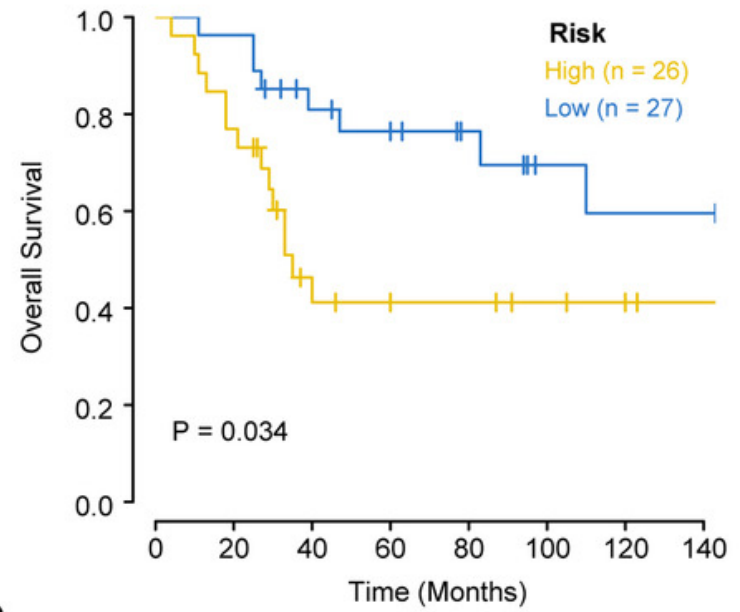

$\mathrm{B}$

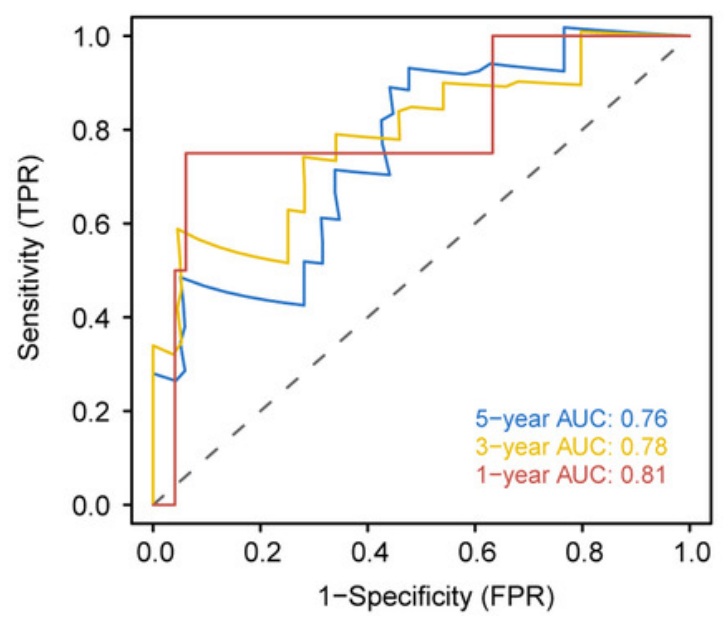

C

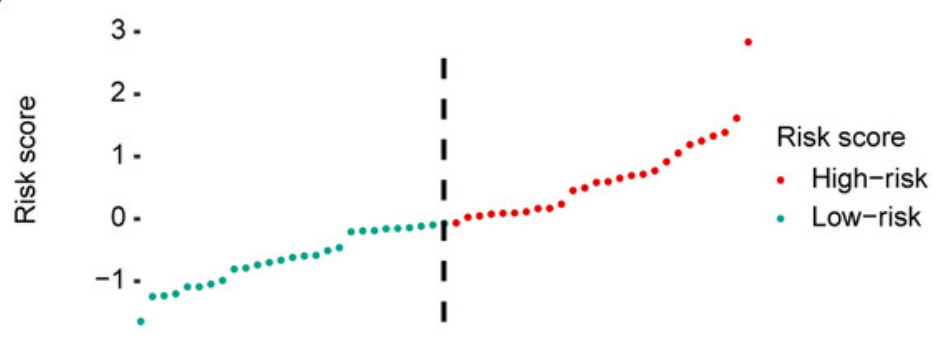

D

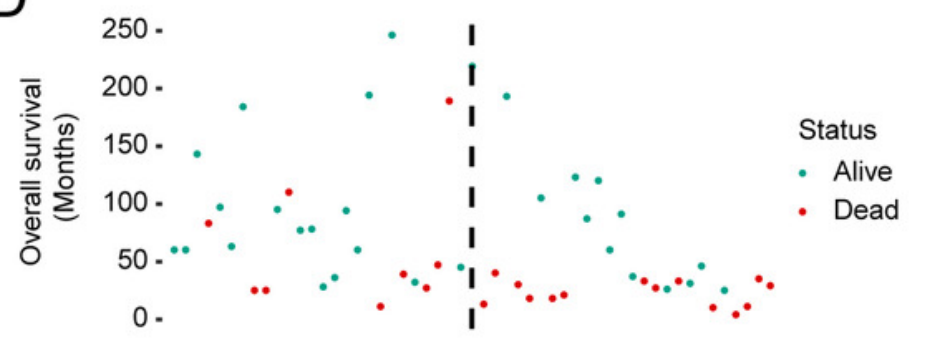

F

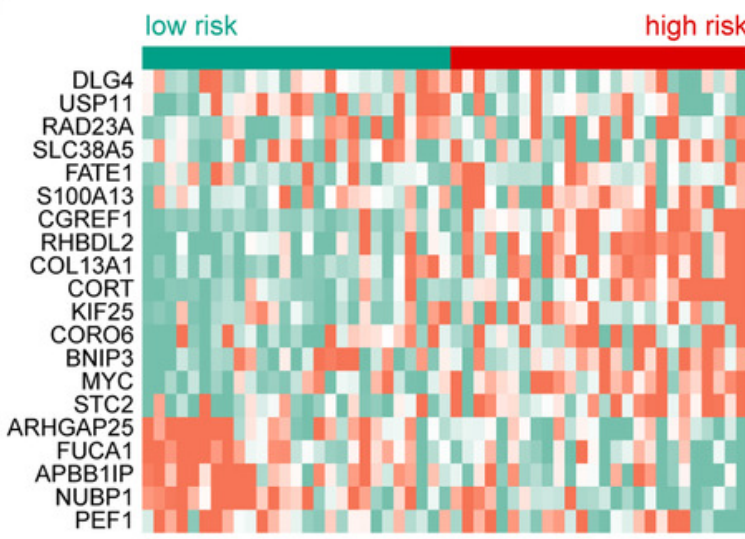

Genes expression

$=1.5$

1.0

0.5

0.0

$-1.0$

$-1.5$ 
Figure 5

Sample cluster analysis to identify outliers underlying RNA sequencing data

The red line suggested the cut-off data filtering in the data preprocessing step c.

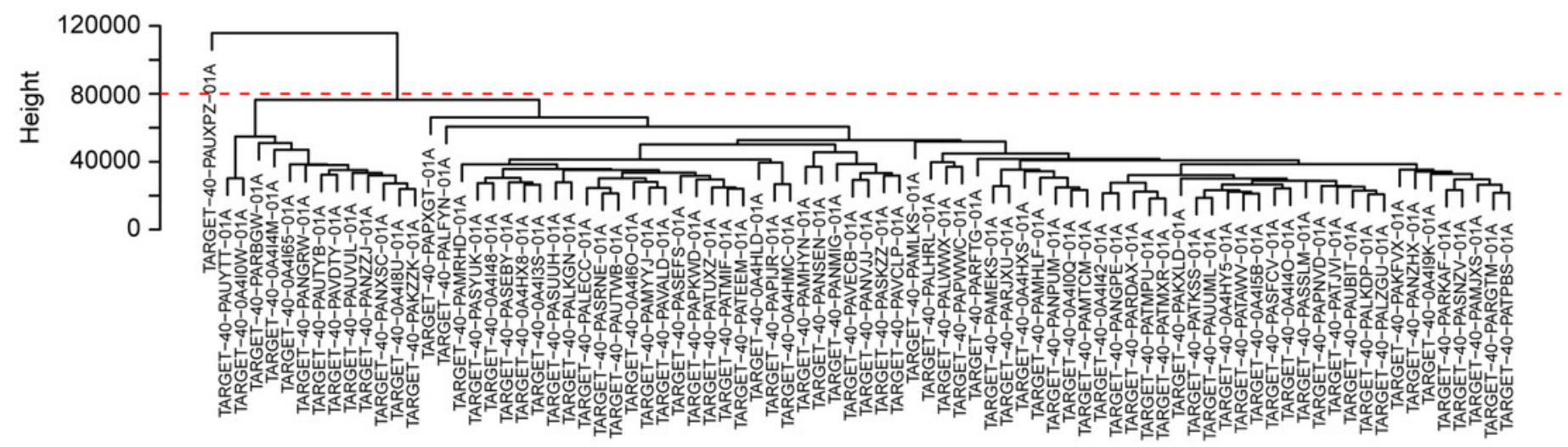




\section{Figure 6}

\section{Overview of co-expression modules identified from the osteosarcoma RN}

A

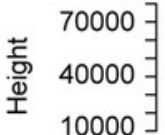

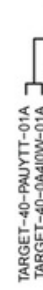

Gender

Age

Recurrence

Overall survival

Metastasis

Primary tumor site

Specific tumor site

Riskscore
$\mathrm{B}$

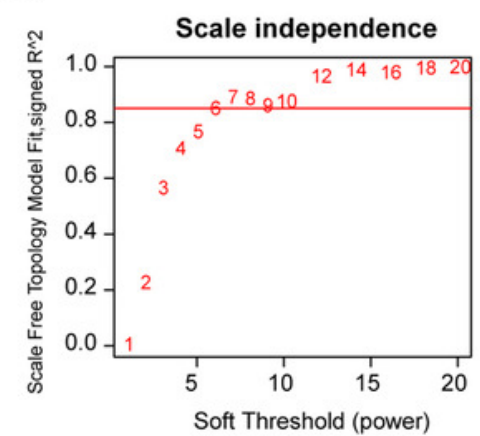

C

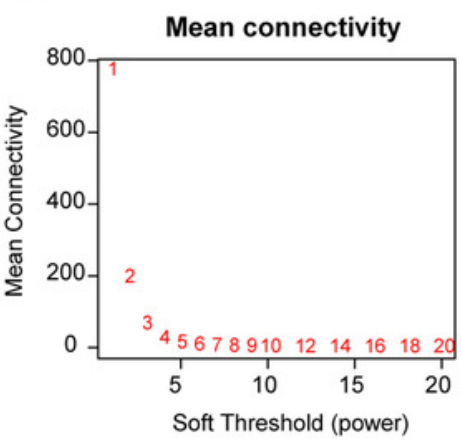

E

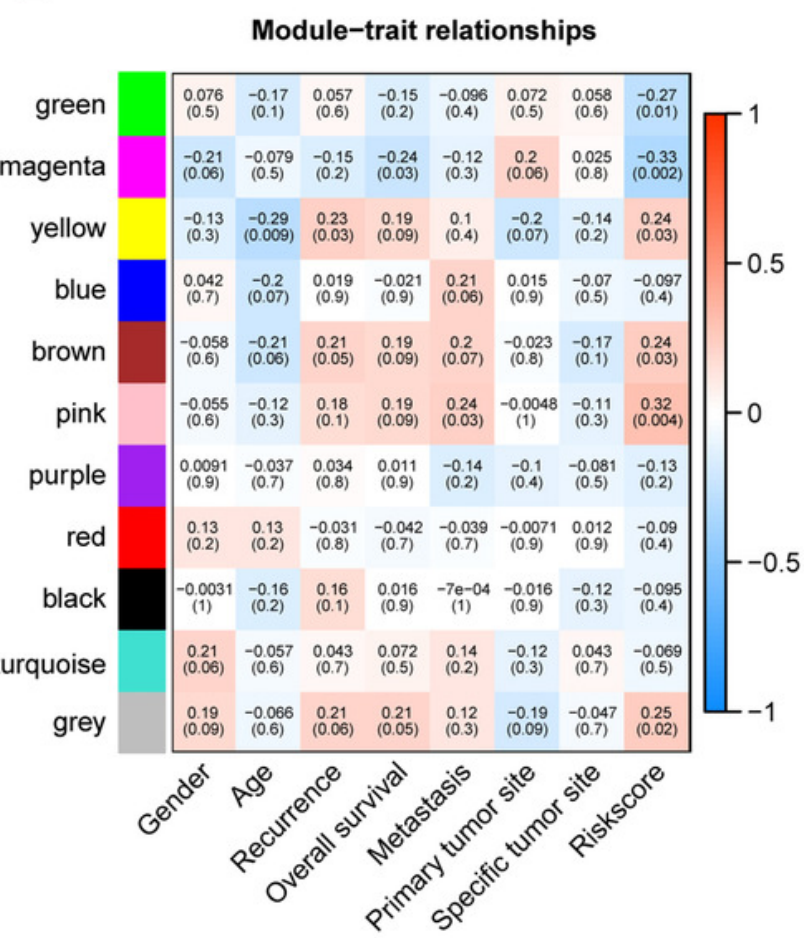




\section{Figure 7}

Functional enrichment analysis and WGCNA weighted network analysis of magenta module

(A) GOplot indicated the correlation between magenta module genes and their related GO terms. (B) GOplot indicated the correlation between magenta module genes and their related KEGG terms.(C) KEGG pathway analysis of magenta module genes based on clusterprofiler.(D) WGCNA weighted network diagram of magenta module. 

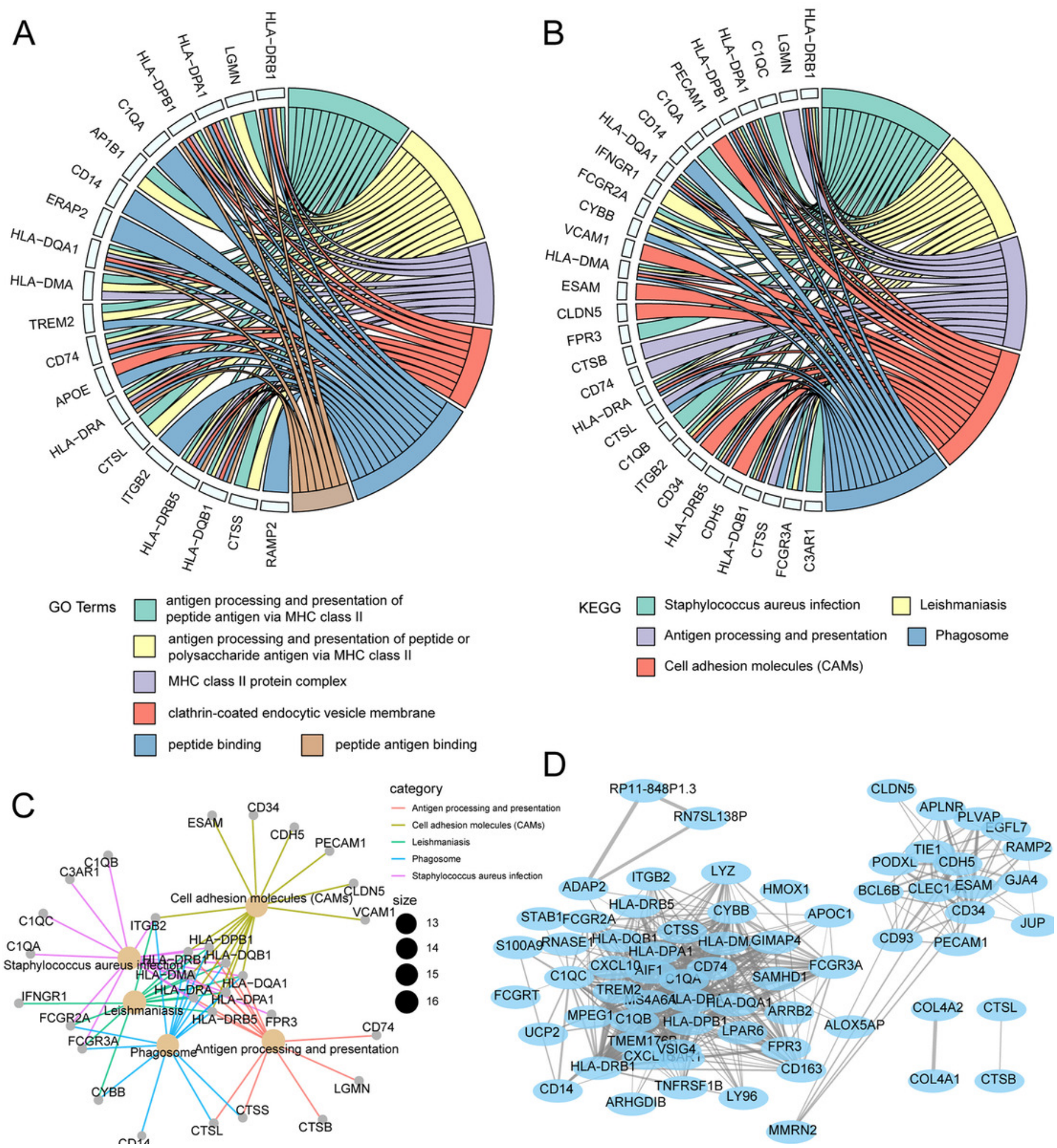
Table $\mathbf{1}$ (on next page)

Potential biomarkers for osteosarcoma 
1 Table 1. Potential biomarkers for osteosarcoma

\begin{tabular}{|c|c|c|c|c|c|c|}
\hline $\begin{array}{l}\text { Study } \\
\text { approach }\end{array}$ & $\begin{array}{l}\text { Type of } \\
\text { biomarker }\end{array}$ & Candidate biomarker & Regulation & Sample & Technique & Reference \\
\hline \multirow[t]{8}{*}{ Genomics } & Diagnostic & C7orf24 & $\uparrow$ & $\begin{array}{l}\text { Tissue; cell } \\
\text { lines }\end{array}$ & $\begin{array}{l}\text { RT-PCR; qRT-PCR; } \\
\text { Western blot } \\
\text { (WB); siRNA transfection }\end{array}$ & $(62)$ \\
\hline & $\begin{array}{l}\text { Diagnostic } \\
\text { And } \\
\text { Predictive }\end{array}$ & miRNA signatures & - & $\begin{array}{l}\text { Tissue; cell } \\
\text { lines }\end{array}$ & qRT-PCR & $(58)$ \\
\hline & Predictive & Multigene classifier & - & Tissue & $\begin{array}{l}\text { cDNA microarray; qRT- } \\
\text { PCR }\end{array}$ & $(60)$ \\
\hline & Predictive & Multigene classifier & - & Tissue & cDNA microarray; RT-PC & $(61)$ \\
\hline & $\begin{array}{l}\text { Predictive } \\
\text { And } \\
\text { Prognosis }\end{array}$ & miRNA signatures & - & Tissue & $\begin{array}{l}\text { miRNA microarray; qRT- } \\
\text { PCR; } \\
\text { immunohistochemistry } \\
\text { (IHC) }\end{array}$ & (59) \\
\hline & $\begin{array}{l}\text { Predictive } \\
\text { And } \\
\text { Prognosis }\end{array}$ & miR-21 & $\uparrow$ & Serum & qRT-PCR & $(51)$ \\
\hline & Prognosis & Tenascin-C & $\downarrow$ & Cell lines & $\begin{array}{l}\text { cDNA microarray; RT- } \\
\text { PCR; } \\
\text { WB; IHC }\end{array}$ & (64) \\
\hline & Prognostic & miRNA-214 & $\uparrow$ & Tissue & qRT-PCR & (63) \\
\hline \multirow[t]{9}{*}{ Proteomics } & Diagnostic & $\begin{array}{l}\text { Serum amyloid A } \\
\text { (SAA) }\end{array}$ & $\uparrow$ & Plasma & SELDI-TOF MS; WB & (71) \\
\hline & Diagnostic & $\begin{array}{l}\text { Ezrin }(\mathrm{EZR}) \text {; a } \\
\text { crystallin } \beta \text { chain } \\
\text { (CRYAB) }\end{array}$ & $\uparrow$ & Tissue & $\begin{array}{l}\text { 2D-DIGE; LC-ESI- } \\
\text { MS/MS; RT-PCR for } \\
\text { mRNA; tissue microarray } \\
\text { and IHC }\end{array}$ & $(66)$ \\
\hline & Diagnostic & $\begin{array}{l}\text { Cytochrome C1 (CYC- } \\
\text { 1) }\end{array}$ & $\uparrow$ & $\begin{array}{l}\text { Serum; cell } \\
\text { lines }\end{array}$ & $\begin{array}{l}\text { SELDI-TOF MS; Gene } \\
\text { microarray (cell lines) }\end{array}$ & $(72)$ \\
\hline & Diagnostic & $\begin{array}{l}\text { Zinc finger protein } 133 \\
\text { (ZNF 133); tubulin-a1c } \\
\text { (TUBA1C) }\end{array}$ & $\uparrow$ & Tissue & $\begin{array}{l}\text { 2-DE; MALDI-TOF MS; } \\
\text { WB; IHC }\end{array}$ & $(70)$ \\
\hline & Diagnostic & Protein NDRG 1 & $\uparrow$ & $\begin{array}{l}\text { Plasma } \\
\text { membrane } \\
\text { from cell } \\
\text { line and } \\
\text { tissue }\end{array}$ & $\begin{array}{l}\text { 2-DE; LC-ESI-MS/MS; } \\
\text { IHC; WB }\end{array}$ & $(67)$ \\
\hline & Diagnostic & Gelsolin & $\downarrow$ & Serum & $\begin{array}{l}\text { 2D-DIGE; MALDIHTOF; } \\
\text { WB; ELISA }\end{array}$ & $(68)$ \\
\hline & $\begin{array}{l}\text { Predictive } \\
\text { And } \\
\text { Prognostic }\end{array}$ & SAA & $\uparrow$ & Serum & $\begin{array}{l}\text { 2D-DIGE; MALDI-TOF } \\
\text { MS; WB; ELISA }\end{array}$ & (2) \\
\hline & Predictive & $\begin{array}{l}\text { Peroxiredoxin } 2 \\
(\text { PRDX2) }\end{array}$ & $\begin{array}{l}\uparrow(\text { poor } \\
\text { prognosis })\end{array}$ & Tissue & $\begin{array}{l}\text { 2D-DIGE; LC-ESI- } \\
\text { MS/MS; WB }\end{array}$ & (69) \\
\hline & Predictive & $\begin{array}{l}\text { SAA; transthyretin } \\
\text { (TTR) }\end{array}$ & $\begin{array}{l}\uparrow(\text { poor } \\
\text { prognosis) }\end{array}$ & Plasma & SELDI-TOF MS; WB & (73) \\
\hline
\end{tabular}




\section{Table 2 (on next page)}

Twenty genes significantly related to the overall survival in the training set underlying the LASSO model 
Table 1 Twenty genes significantly related to the overall survival in the training set underlying the LASSO model

\begin{tabular}{|c|c|c|c|c|c|}
\hline Ensemble ID & Gene & Chromosome location & $\begin{array}{c}\text { Coefficient of lasso } \\
\text { model }\end{array}$ & HR & pvalue \\
\hline ENSG00000103274.9 & NUBP1 & chr16:10743786-10769351:(+) & -0.2216 & $\begin{array}{l}0.905(0.86 \\
0.953)\end{array}$ & 0.000 \\
\hline ENSG00000163219.10 & ARHGAP25 & chr2:68679601-68826833:(+) & -0.0503 & $\begin{array}{l}0.795(0.685 \\
0.924)\end{array}$ & 0.003 \\
\hline ENSG00000077420.14 & APBB1IP & chr10:26438203-26567803:(+) & -0.0429 & $0.924(0.88,0.97)$ & 0.001 \\
\hline ENSG00000162517.11 & PEF1 & chr1:31629862-31644896:(-) & -0.0230 & $\begin{array}{l}0.979(0.966 \\
0.992)\end{array}$ & 0.002 \\
\hline ENSG00000102226.8 & USP11 & chrX:47232690-47248328:(+) & -0.0123 & $\begin{array}{l}0.982(0.97 \\
0.994)\end{array}$ & 0.004 \\
\hline ENSG00000179163.11 & FUCA1 & chr1:23845077-23868294:(-) & -0.0104 & $\begin{array}{c}0.969(0.949 \\
0.99)\end{array}$ & 0.003 \\
\hline ENSG00000189171.12 & S100A13 & chr1:153618787-153634092:(- & 0.0019 & $\begin{array}{l}1.007(1.004 \\
1.011)\end{array}$ & 0.000 \\
\hline ENSG00000132535.17 & DLG4 & chr17:7189890-7219702:(-) & 0.0088 & $\begin{array}{c}1.064(1.021 \\
1.109)\end{array}$ & 0.003 \\
\hline ENSG00000158315.9 & RHBDL2 & chr1:38885807-38941799:(-) & 0.0144 & $\begin{array}{c}1.01(1.006 \\
1.013)\end{array}$ & 0.000 \\
\hline ENSG00000176171.10 & BNIP3 & $\begin{array}{c}\text { chr10:131966455- } \\
\text { 131981931:(-) }\end{array}$ & 0.0170 & $\begin{array}{c}1.009(1.004 \\
1.014)\end{array}$ & 0.000 \\
\hline ENSG00000167549.17 & CORO6 & chr17:29614756-29622907:(-) & 0.0425 & $\begin{array}{c}1.054(1.021 \\
1.088)\end{array}$ & 0.001 \\
\hline ENSG00000125337.15 & KIF25 & $\begin{array}{l}\text { chr6:167996241- } \\
\text { 168045089:(+) }\end{array}$ & 0.0570 & $\begin{array}{l}1.148(1.076 \\
1.224)\end{array}$ & 0.000 \\
\hline ENSG00000179262.8 & RAD23A & chr19:12945855-12953642:(+) & 0.0741 & $\begin{array}{c}1.005(1.002 \\
1.008)\end{array}$ & 0.000 \\
\hline ENSG00000147378.10 & FATE1 & $\begin{array}{l}\operatorname{chrX}: 151716035- \\
151723194:(+)\end{array}$ & 0.0862 & $\begin{array}{l}2.217(1.518 \\
\quad 3.238)\end{array}$ & 0.000 \\
\hline ENSG00000113739.9 & STC2 & $\begin{array}{c}\text { chr5:173314713-173329503:(- } \\
)\end{array}$ & 0.0895 & $\begin{array}{c}1.016(1.005 \\
1.027)\end{array}$ & 0.004 \\
\hline ENSG00000197467.12 & COL13A1 & chr10:69801931-69964275:(+) & 0.0910 & $1.021(1.013$ & 0.000 \\
\hline
\end{tabular}




\begin{tabular}{|c|c|c|c|c|c|}
\hline Ensemble ID & Gene & Chromosome location & $\begin{array}{c}\text { Coefficient of lasso } \\
\text { model }\end{array}$ & HR & pvalue \\
\hline ENSG00000017483.13 & SLC38A5 & chrX:48458537-48470256:(-) & 0.1003 & $\begin{array}{c}1.029) \\
1.008(1.003 \\
1.014)\end{array}$ & 0.002 \\
\hline ENSG00000136997.13 & MYC & $\begin{array}{c}\text { chr8:127735434- } \\
\text { 127741434:(+) }\end{array}$ & 0.1635 & $\begin{array}{c}1.003(1.002, \\
1.005)\end{array}$ & 0.000 \\
\hline ENSG00000138028.13 & CGREF1 & chr2:27098889-27119115:(-) & 0.2105 & $\begin{array}{c}1.015(1.009 \\
1.021)\end{array}$ & 0.000 \\
\hline ENSG00000241563.3 & CORT & chr1:10449719-10451902:(+) & 0.2504 & $\begin{array}{c}1.026(1.016 \\
1.036)\end{array}$ & 0.000 \\
\hline
\end{tabular}

2 HR: Hazard Ratio; CI: Confidence Interval 


\section{Table 3(on next page)}

Univariate and multivariate Cox regression analyses genes signiture for patients with osteosarcoma in study cohort. 
1 Table3. Univariate and multivariate Cox regression analyses genes signiture for patients 2 with osteosarcoma in study cohort.

3

\begin{tabular}{|c|c|c|c|c|}
\hline \multirow[b]{2}{*}{ Characteristics } & \multicolumn{2}{|c|}{ Univariate } & \multicolumn{2}{|c|}{ Multivariate } \\
\hline & $\mathrm{HR}$ & p.value & $\mathrm{HR}$ & p.value \\
\hline Gender (Female vs Male) & $0.666(0.317,1.399)$ & 0.283 & & \\
\hline Age (<18 vs $>=18)$ & $0.909(0.345,2.393)$ & 0.846 & & \\
\hline Recurrence (No vs Yes) & $19.348(4.589,81.563)$ & $<0.001$ & $5.374(1.183,24.404)$ & 0.029 \\
\hline \multicolumn{5}{|l|}{ Primary tumor site } \\
\hline \multicolumn{5}{|l|}{ (Arm/Hand OR Pelvis vs } \\
\hline Leg/Foot) & $0.487(0.168,1.413)$ & 0.185 & & \\
\hline \multicolumn{5}{|c|}{ Specific tumor site (Femur vs } \\
\hline Tibia or others) & $0.642(0.309,1.337)$ & 0.236 & & \\
\hline riskscore & $13.915(7.067,27.398)$ & $<0.001$ & $9.869(4.663,20.887)$ & $<0.001$ \\
\hline
\end{tabular}




\section{Table 4 (on next page)}

Relationship between risk score of the 20-marker-based prognostic classifier with os and clinical characteristics in the training set 
1 Table 4 Relationship between risk score of the 20-marker-based prognostic classifier with os and clinical

2 characteristics in the training set

\begin{tabular}{|c|c|c|c|c|}
\hline Characters & Level & Low risk & High risk & $P$ value \\
\hline $\mathrm{n}$ & & 42 & 42 & \\
\hline \multirow[t]{2}{*}{ Gender } & Female (\%) & $16(38.1)$ & $21(50.0)$ & 0.379 \\
\hline & Male $(\%)$ & $26(61.9)$ & $21(50.0)$ & \\
\hline \multirow[t]{2}{*}{ Age } & $<18(\%)$ & $32(76.2)$ & $34(81.0)$ & 0.791 \\
\hline & $>=18(\%)$ & $10(23.8)$ & $8(19.0)$ & \\
\hline \multirow[t]{2}{*}{ Overall survival } & Alived (\%) & $42(100.0)$ & $13(31.0)$ & $<0.001$ \\
\hline & Dead $(\%)$ & $0(0.0)$ & $29(69.0)$ & \\
\hline \multirow[t]{2}{*}{ Recurrence } & No $(\%)$ & $32(76.2)$ & $13(31.0)$ & $<0.001$ \\
\hline & Yes $(\%)$ & $10(23.8)$ & $29(69.0)$ & \\
\hline \multirow[t]{2}{*}{ Metastasis } & No $(\%)$ & $37(88.1)$ & $26(61.9)$ & 0.011 \\
\hline & Yes $(\%)$ & $5(11.9)$ & $16(38.1)$ & \\
\hline \multirow[t]{2}{*}{ Primary tumor site } & Arm/Hand OR Pelvis (\%) & $3(7.1)$ & $5(11.9)$ & 0.713 \\
\hline & Leg/Foot (\%) & $39(92.9)$ & $37(88.1)$ & \\
\hline \multirow[t]{2}{*}{ Specific tumor site } & Femur (\%) & $13(31.0)$ & $25(59.5)$ & 0.015 \\
\hline & Tibia or others $(\%)$ & $29(69.0)$ & $17(40.5)$ & \\
\hline
\end{tabular}

